\title{
Desain Playground Budaya sebagai Media untuk Menanamkan Cinta Tanah Air pada Anak Usia Dini
}

\author{
M. Fadlillah ${ }^{1 凶}$, Ida Yeni Rahmawati ${ }^{1}$, Rendy Setyowahyudi ${ }^{1}$ \\ Pendidikan Guru Pendikan Anak Usia Dini, Universitas Muhammadiyah Ponorogo, \\ Indonesia ${ }^{(1)}$ \\ DOI: 10.31004/obsesi.v6i4.2380
}

\begin{abstract}
Abstrak
Playground bagi anak usia dini merupakan tempat bermain dan sarana belajar yang menyenangkan. Playground dapat dimanfaatkan sebagai media untuk mengenal berbagai kebudayaan Indonesia. Selama ini playground hanya digunakan untuk bermain bebas oleh anak-anak. Padahal apabila dirancang dan digunakan dengan baik playground dapat membantu menumbuhkan rasa cinta tanah air Indonesia. Tujuan dari penelitian ini adalah untuk mengembangkan desain playground budaya sebagai media untuk menanamkan cinta tanah air pada anak usia dini. Metode penelitian yang digunakan yaitu research and development (R\&D), meliputi: analisi masalah, pengumpulan data, perencanaan desain, validasi, dan pembuatan desain playground budaya. Hasil penelitian menunjukkan bahwa desain playground budaya yang dibuat terdiri dari 1 ayunan, 1 seluncuran, 1 jungkat-jungkit, 1 kazebo, dan 1 gapura. Masing-masing sarana permainan tersebut diintegrasikan dengan unsur kebudayaan Indonesia. Dengan playground budaya ini diharapkan mampu menumbuhkan semangat cinta tanah air pada anak usia dini.
\end{abstract}

Kata Kunci: playground budaya; cinta tanah air; kebudayaan Indonesia; anak usia dini.

\begin{abstract}
Playground for early childhood is a place to play and a fun learning tool. Playground can be used as a medium to get to know various Indonesian cultures. So far, the playground is only used for free play by children. In fact, if properly designed and used, playgrounds can help foster a sense of love for the Indonesian homeland. The purpose of this research is to develop a cultural playground design as a medium to instill love for the homeland in early childhood. The research method used is research and development (R\&D), including: problem analysis, data collection, design planning, validation, and making cultural playground designs. The results showed that the cultural playground design made consisted of 1 swing, 1 slide, 1 seesaw, 1 kazebo, and 1 gate. Each of these game facilities is integrated with elements of Indonesian culture. With this cultural playground, it is hoped that it can foster the spirit of love for the homeland in early childhood.
\end{abstract}

Keywords: cultural playground; love for the homeland; Indonesian culture; early childhood.

Copyright (c) 2022 M. Fadlillah, et al.

$\triangle$ Corresponding author :

Email Address : fadly_ok@yahoo.co.id (Ponorogo, Indonesia)

Received 4 November 2021, Accepted 20 February 2022, Published 25 February 2022 


\section{PENDAHULUAN}

Cinta tanah air sangat penting di tengah-tengah kemajuan dan perkembangan zaman. Cinta tanah air dapat memperkokoh persatuan dan kesatuan bangsa. Cinta tanah air akan mampu menumbuhkan sikap peduli, rela berkorban, dan semangat pengabdian untuk keutuhan dan persatuan bangsa. Perasaan cinta tanah air haruslah dimiliki oleh setiap warga negara Indonesia (Rahayu, 2017). Rasa cinta tanah air perlu ditanamkan mengingat semakin majunya perkembangan zaman ke arah modernisasi serta gempuran budaya asing yang masuk ke Indonesia sehingga banyak remaja yang melupakan budanya sendiri dan lebih mencintai budaya asing yang masuk ke Indonesia (Amalia et al., 2020). Oleh karena itu, cinta tanah air harus ditanamkan sejak dini supaya dapat terpatri kuat dalam diri anak usia dini.

Upaya yang dapat dilakukan dalam menanamkan cinta tanah air pada anak usia dini ialah dengan mengenalkan berbagai kebudayaan nasional. Seseorang yang memiliki cinta tanah air salah satunya ialah ditandai dengan mampu menghargai karya seni dan budaya Indonesia (Wisnarni, 2017). Rasa cinta tanah air juga ditandai dengan rela berkorban demi kepentingan bangsa dan negara, serta memiliki kecintaan terhadap kebudayaan Indonesia.

Untuk menumbuhkan perasaan cinta tanah air maka harus dikenalkan dengan budayanya sendiri. Budaya adalah suatu bentuk cara hidup yang dimiliki bersama oleh kelompok orang atau masyarakat dan diwariskan dari generasi ke generasi (Fadlillah et al., 2022). Dengan mengenal budayanya sendiri anak-anak dapat terhindar dari pengaruh budaya asing (Atika et al., 2019). Salah satu cara mengenalkan kebudayaan Indonesia pada anak usia dini ialah melalui bermain. Menurut Parten sebagaimana dikutip Fadlillah (2018) menjelaskan bahwa bermain merupakan suatu kegiatan sebagai sarana bersosialisasi dan dapat memberikan kesempatan anak bereksplorasi, menemukan, mengekspresikan perasaan, berkreasi, dan belajar secara menyenangkan. Di samping itu, usia dini merupakan masanya anak untuk bermain. Oleh karena itu, bermain harus dapat dimanfaatkan sebagai sarana belajar bagi anak usia dini.

Belajar melalui bermain merupakan salah satu karakteristik yang dimiliki oleh anak usia dini. Bermain bagi mereka adalah belajar yang paling efektif (Fadlillah, 2018). Anak usia dini banyak menghabiskan sebagian besar waktunya untuk bermain (Wahyuni \& Azizah, 2020). Menurut Zaini (2019) bermain merupakan metode pembelajaran bagi anak usia dini. Bermain dapat mengembangkan kreativitas dan kognitif anak usia dini. Dengan bermain anak dapat belajar banyak hal tentang sekitarnya, termasuk kebudayaan Indonesia.

Untuk dapat memfasilitasi kegiatan bermain anak maka dibutuhkan playground atau lebih dikenal dengan tempat bermain yang representative bagi anak. Tempat bermain untuk anak usia dini terus berkembang sesuai dengan kebutuhan dan perubahan jaman (Luchs \& Fikus, 2013). Untuk itu penyediaan playground bagi anak usia dini merupakan prioritas yang harus diutamakan. Tempat bermain bagi anak usia dini memiliki tujuan agar anak dapat bergerak dan bermain secara aktif (Zaim et al., 2015). Diketahui bahwa bermain di playground memberikan banyak manfaat bagi perkembangan anak, termasuk mengenalkan budaya sehingga rasa cinta pada tanah air dapat tertanam sejak usia dini. Hal ini perlu dilakukan sebab rasa cinta tanah air sudah mulai pudar di kalangan anak-anak. Oleh karena itu, perlu ditanamkan sejak usia dini. Salah satunya melalui bermain berbasis kebudayaan Indonesia. Penyediaan playground yang menarik haruslah diciptakan untuk anak.

Menyediakan playground bagi anak usia dini haruslah memperhatikan aspek fisik dan nonfisik (Mariyana \& Setiasih, 2018). Aspek fisik meliputi kelengkapan material, ukuran, luas, berat arah dan sebagainya, sementara aspek nonfisik yaitu pertimbangan rasa aman, minat dan rasa ingin tahu anak, kebebasan berekspresi, membangun rasa percaya diri, aktualisasi diri, menyalurkan emosi dan rasa kegembiraan (Mariyana \& Setiasih, 2018). Playground bagi anak usia dini haruslah memperhatikan aspek alat permainan yang ada di dalamnya untuk memenuhi kebutuhan anak, pengasuh dan guru (Stanton-Chapman \& Schmidt, 2019). Selama ini tempat bermain anak usia dini telah banyak dikembangkan, namun sebagian besar lebih berfokus pada faktor keamanan saja, belum banyak yang berfokus pada manfaat aspek 
perkembangan yang akan didapatkan oleh anak (Little \& Eager, 2010). Di samping itu, pengembangan playground yang berfokus pada manfaat untuk anak masih terbatas (Mariyana \& Setiasih, 2018).

Berdasarkan permasalahan di atas maka penelitian ini dimaksudkan untuk mengembangkan desain playground budaya sebagai media menanamkan rasa cinta tanah air pada anak usia dini. Playground budaya dirancang dengan mengintegrasikan unsur-unsur kebudayaan Indonesia. Selama ini playground hanya sebatas zona bermain bebas anak, namun dengan playground budaya anak-anak dapat bermain sekaligus mengenal berbagai kebudayaan yang dimiliki bangsa Indoensia. Untuk itu, melalui desain playground budaya ini diharapkan tercipta playground yang dapat dimanfaatkan sebagai media untuk mengenalkan kebudayaan Indonesia yang menarik dan menyenangkan.

\section{METODOLOGI}

Untuk dapat mengembangkan dan menghasilkan produk berupa playground budaya sebagai media untuk menanamkan cinta tanah air pada anak usia dini penelitian ini menggunakan metode research and development $(\mathrm{R} \& \mathrm{D})$. Metode ini dipilih karena sangat tepat dan sesuai dengan tujuan penelitian, yaitu mengembangkan playground budaya untuk anak usia dini. Model pengembangan ini mengacu pada pendapat Borg (2007) yaitu terdiri dari mengembangkan produk dan menguji kelayakan produk. Metode R\&D dimaksudkan untuk menghasilkan produk yang dapat diuji kelayakan maupun kefektifannya (Sugiyono, 2011). Proses penelitian dan pengembangan ini dapat dilihat pada gambar 1 .

Pengumpulan data penelitian dilakukan dengan melakukan wawancara, studi literatur dan kegiatan focus group discussion (FGD). Wawancara dilakukan kepada kepala dan guru TK Negeri Pembina Ponorogo. Studi literature dilakukan dengan mengkaji dan mengalisis berbagai kebudayaan Indonesia melalui buku, artikel ilmiah, dan berita online. Adapun untuk FGD dilakukan dengan mendatangkan para ahli di bidang alat permainan anak usia dini dan pendidikan pancasila dan kewarganegaraan, terdiri dari 2 akademisi dan 10 guru pendidikan anak usia dini.

Pengembangan dalam penelitian tahap awal ini dilakukan hanya untuk menghasilkan produk berupa desain playground budaya sebagai media untuk menanamkan cinta tanah air pada anak usia dini. Adapun prosedur dan tahapan pengembangan yang dilakukan dalam menghasilkan desain playground budaya ini yaitu: melakukan analisis kebudayaan Indonesia dan karakteristik playground anak usia dini, pemilihan kebudayaan yang dapat diintegrasikan dalam playground anak usia dini, dan membuat desain playground budaya untuk anak usia dini, serta melakukan focus group discussion (FGD) untuk mengetahui kelayakan desain playground budaya. Alur penelitian diilustrasikan dengan bagan pada gambar 1 .

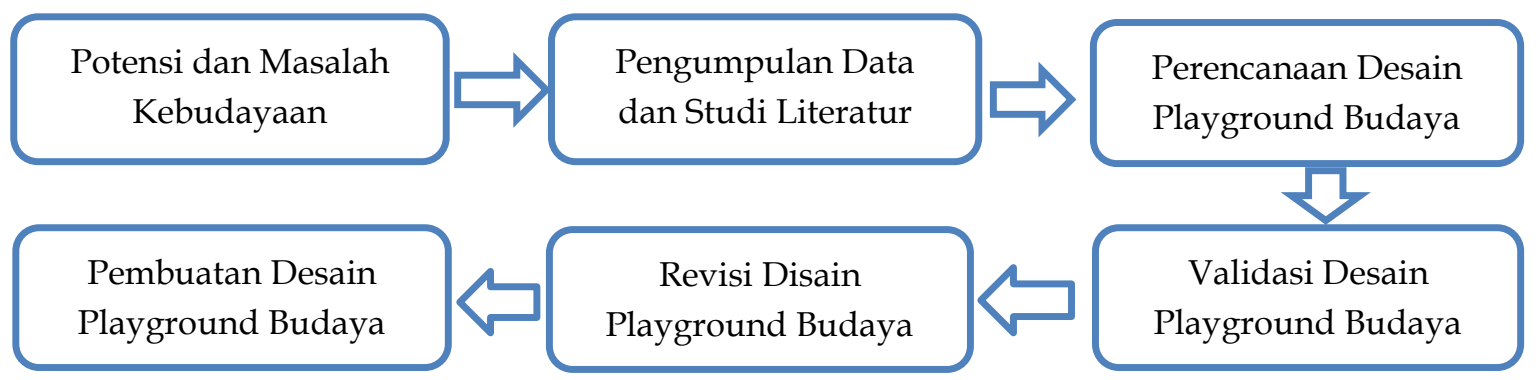

\section{Gambar 1. Alur penelitian dan pengembangan playground budaya}

Analisis kebudayaan untuk playground budaya dilakukan dengan mengkaji berbagai refrensi tentang berbagai kebudayaan di Indonesia. Dari analisis ini selanjutnya ditentukan beberapa kebudayaan yang sesuai dan dapat diintergrasikan dalam bentuk playground budaya. Proses desain playground budaya dilakukan dengan melibatkan pihak eksternal 
yaitu seorang desainer professional yang memiliki keahlian dalam mendesain playground budaya untuk anak usia dini. Adapun kegiatan FGD dilakukan dengan melibatkan akademisi dan praktisi di bidangnya masing-masing, di antaranya: 1 dosen pendidikan pancasila dan kewarganegaraan, 1 dosen pendidikan guru pendidikan anak usia dini, 2 orang pengawas/penilik PAUD, dan 10 guru taman kanak-kanak di Ponorogo.

\section{HASIL DAN PEMBAHASAN}

Pelaksanaan penelitian tentang pengembangan desain playground budaya sebagai media untuk menanamkan nilai cinta tanah air pada anak usia dini ini dibagi menjadi dua tahapan, yaitu identifikasi masalah dan proses pengembangan produk. Identifikasi masalah dilakukan dengan mengkaji dan mengidentifikasi beberapa budaya Indonesia yang cocok dan dapat diintegrasikan dalam playground anak usia dini. Peneliti mengkaji jenis playground termasuk alat permainan apa yang biasanya ada dalam playground untuk anak usia dini dan syarat playground yang baik untuk anak usia dini. Berdasarkan hasil identifikasi diketahui bahwa playground merupakan area bermain baik itu indoor ataupun outdoor bagi anak usia dini. Hal tersebut didukung oleh pendapat Firdaus et al. (2020) playground adalah area untuk bermain atau taman bermain yang dapat dipergunakan sebagai area untuk bermain anakanak atau tempat wisata anak. Sementara itu jenis playground pada anak usia dini terbagi menjadi lima yaitu permainan fisik yang memungkinkan anak bergerak aktif, permainan kreatif yang membutuhkan imajinasi anak, permainan sosial yang menitik beratkan pada hubungan sosial anak, permainan yang menggunakan pancaindera anak dan permainan ketenangan yang memungkinkan anak beristirahat dan berpikir (Santoso, 2019). Untuk syarat playground yang baik harus memenuhi diantaranya adalah sesuai dengan anatomi tubuh, aman, fleksibel, kuat dan ujungnya tidak tajam (Santoso, 2019). Playground harus memprioritaskan keamanan, keselamatan, kenyamanan dan keindahan supaya dapat menjadi sarana bermain yang baik untuk perkembangan anak (Baskara, 2011).

\section{Pengembangan Desain Playground Budaya}

Proses pengembangan desain playground dilakukan setelah mendapatkan unsur budaya yang akan diintegrasikan. Desain playground budaya untuk anak usia dini dirancang dengan memenuhi unsur kebudayaan Indonesia. Di samping juga memperhatikan keamanan dan keselamatan. Untuk mendapatkan desain yang baik, peneliti menggunakan jasa desainer yang berkompeten di bidangnya.

Proses pembuatan desain playground budaya sebagai media untuk menanamkan cinta tanah air ini dilakukan sebanyak beberapa kali revisi. Hal ini dimaksudkan supaya dapat diperoleh desain yang tepat dan memenuhi unsur budaya, serta memperhatikan kebutuhan dan tahapan perkembangan anak usia dini. Bentuk desain playground budaya pada awal atau sebelum dilakukan perbaikan dapat dilihat pada gambar 2 .

Dari hasil desain playground pada gambar 2 tersebut selanjutnya dikaji dan dianalisis oleh tim penelitian dengan melibatkan akademisi dan praktisi pendidikan anak usia dini. Dari hasil evaluasi playground tersebut harus diperbaiki karena tampilan kurang menarik dan unsur kebudayaannya belum terlihat. Adapun bentuk desain playground budaya yang sudah diperbaiki dapat dilihat pada gambar 3 .

Setelah dilakukan kajian dan analisis terhadap desain playground budaya pada gambar 3 tersebut diputuskan untuk dilakukan perbaikan kembali, sebab unsur budayanya belum terlihat jelas. Oleh karena itu, perbaikan untuk yang ketiga kalinya dilakukan dengan memfokuskan pada unsur budayanya. Dari hasil perbaikan maka bentuk desain playground budaya dapat dilihat pada gambar 4 . 


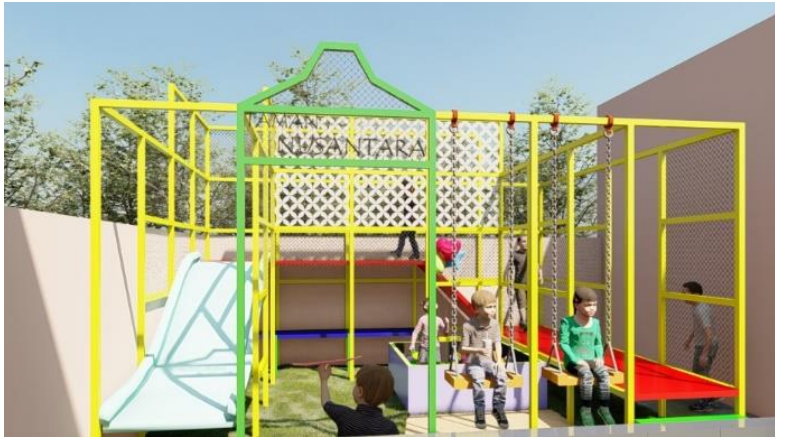

Gambar 2. Desain playground budaya sebelum revisi

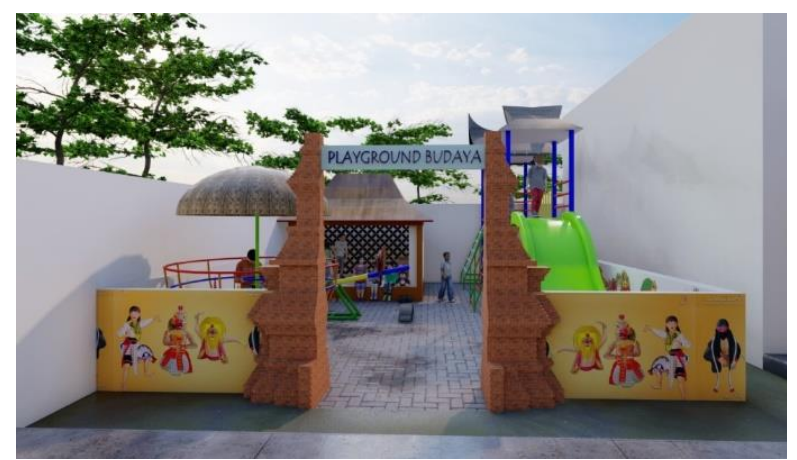

Gambar 4. Desain akhir playground budaya setelah revisi kedua (Tampak depan)

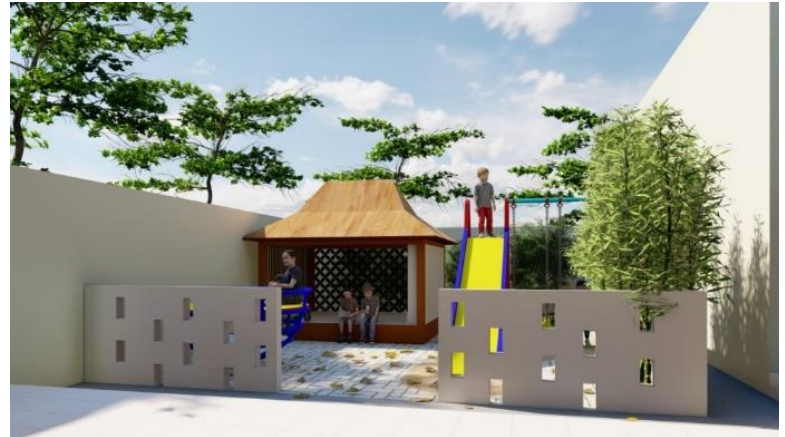

Gambar 3. Desain playground budaya setelah revisi pertama

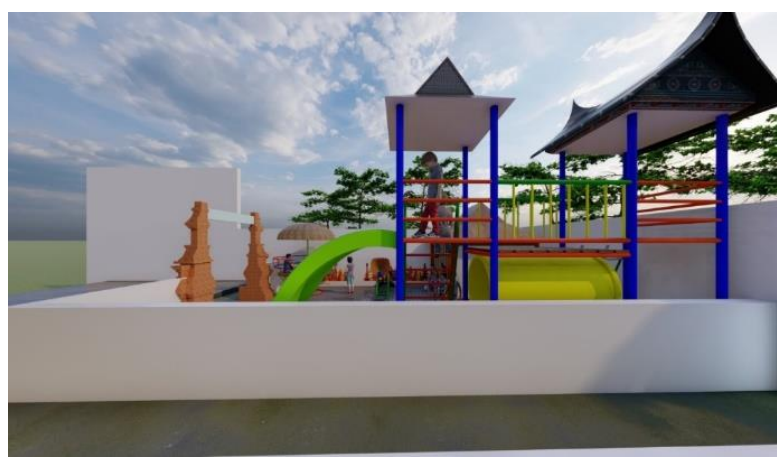

Gambar 6. Desain playground budaya tampak samping

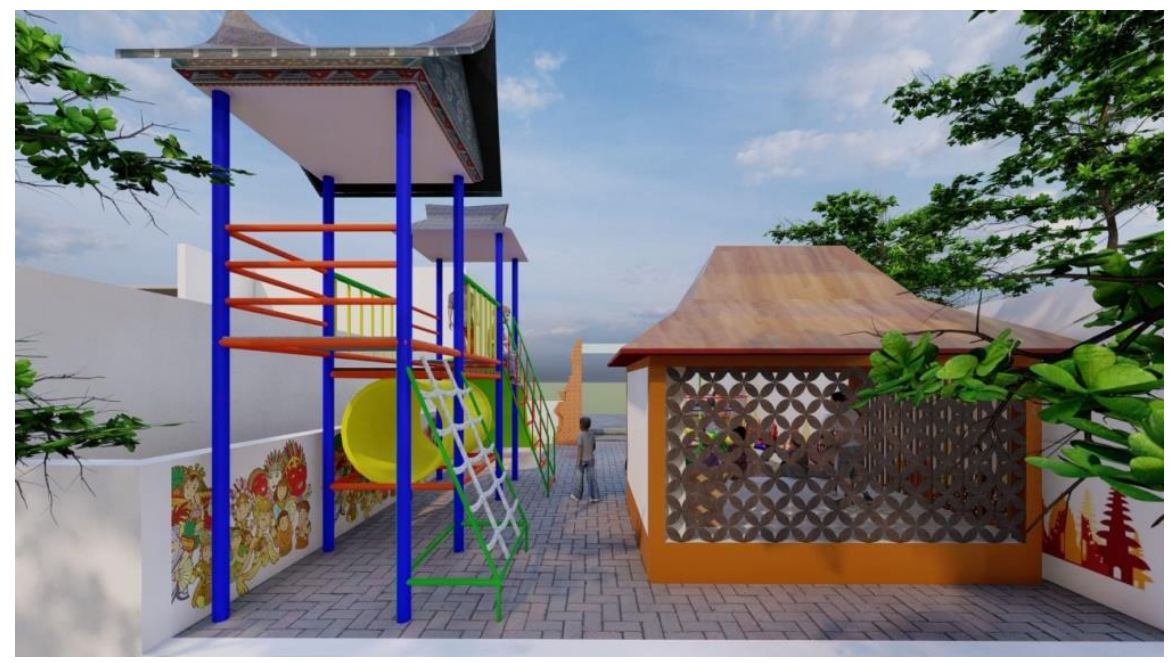

Gambar 7. Desain playground budaya tampak belakang

\section{Klasifikasi Bentuk Playground Budaya}

Pada playground budaya Indonesia terdapat beberapa fasilitas dan alat bermain yang mengandung unsur budaya didalamnya adapun fasilitas dan alat bermain tersebut di antaranya perosotan/seluncuran, jungkat-jungkit, gazebo, mangkok putar, terowongan, gapura dan dinding pembatas playground budaya. Masing-masing komponen dan spesifikasi alat permainan dalam desain playground budaya akan dijelaskan dalam pembahasan ini. Adapun beberapa penampakan desain playground budaya secara lengkap sebagai disajikan pada gambar 4,5 dan 6 . 
Perosotan yang dibuat dalam playground budaya ini adalah memiliki warna hijau menarik yang disukai anak, memiliki gambar angka dalam aksara jawa yang berfungsi sebagai pengenalan budaya jawa pada anak, memiliki anak tangga yang terstandar baik dari ukuran dan juga permukaannya, memiliki ralling besi untuk melindungi anak dari bahaya jatuh kesamping, memiliki parapet yang digunakan agar anak dapat meluncur sesuai jalur dan dapat digunakan anak untuk berpengangan saat meluncur agar tidak jatuh, memiliki dasaran perosotan yang terbuat dari pasir yang empuk sebagai pijakan anak saat mendarat dari perosotan dan memiliki atap dengan bentuk atap rumah bolon di puncaknya sebagai pelindung dari panas dan juga sebagai media untuk pengenalan budaya rumah adat Jawa bagi anak usia dini.

Pada permainan jungkat-jungkit yang dibuat untuk playground budaya ini selain sudah memenuhi standar juga menambahkan unsur budaya didalamnya. Adapun unsur budaya yang ditambahkan adalah pada bagian pegangan disetiap sudut permainan jungkatjungkit. Dimana pada pegangan tersebut diberikan tambahan berupa topeng wajah ondelondel yang berbentuk raksasa sebagai unsur budaya betawi yang ingin dikenalkan pada anak usia dini dan diharapkan mampu menciptakan rasa cinta tanah air pada diri anak. Sementara pada permainan mangkok putar yang akan dibuat untuk playground berbasis budaya Indonesia ini terdapat beberapa spesifikasi diantaranya tempat duduk dengan alas kayu yang nyaman, bahan mangkok putar terbuat dari besi yang kokoh, kemudi dibagian tengah, warna mangkok putar cerah dan menarik dan juga terdapat tambahan komponen yaitu penutup mangkok putar yang berbentuk seperti atap rumah adat papua (honai).

Selanjutnya, pada gazebo yang terdapat pada playground berbasis budaya Indonesia ini memiliki beberapa komponen seperti gazebo pada umumnya, namun terdapat tambahan komponen yang dapat membantu anak mengenal kebudayaan Indonesia lebih dekat lagi. Adapun komponen dari gazebo yang akan dibuat adalah berbahan kayu sebagai bahan pokok bangunan gazebo, beratapkan atap rumah joglo sebagai media pengenalan kebudayaan rumah adat Indonesia, memiliki tembok belakang yang memiliki motif batik segiempat sebagai pengenalan budaya batik Indonesia dan memiliki fasilitas rak tempat penyimpanan alat permainan edukatif tradisional dari berbagai daerah di Indonesia sebagai media pengenalan budaya Indonesia melalui permainan tradisonal daerah.

Pada permainan terowongan yang ada dalam playground budaya memiliki komponen memiliki ukuran terowongan yang besar sehingga memudahkan anak untuk melewatinya, memiliki warna kuning yang ceria, memiliki atap berbentuk rumah gadang sebagai media untuk pengenalan budaya pada anak.

Gapura yang digunakan dalam playground sebagai pintu masuk adalah jenis gapura belah bentar yang memiliki arsitektur jawa kuno. Gapura jenis ini dipilih karena dapat memberikan kemudahan akses masuk bagi anak saat ingin bermain playground. Selain itu penggunaan gapura sebagai pintu masuk juga memiliki tujuan untuk mengenalkan budaya Indonesia melalui arsitektur gapura khas Indonesia sehingga anak nanti dapat memiliki sikap cinta terhadap tanah air Indonesia dan dinding pembatas pada playground ini juga difungsikan sebagai media pengenalan budaya reyog ponorogo karena dinding pembatas pada playground ini di lukis dengan berbagai tokoh yang ada dalam kesenian reyog ponorogo.

Desain playground budaya di atas telah dirancang dengan memperhatikan prinsipprinsip pembuatan playground untuk anak usia dini. Menurut Mariyana sebagaimana dikutip oleh (Diningrat, 2019) bahwa prinsip yang harus diperhatikan dalam membuat playground adalah keselamatan, keamanan, sesuai kebutuhan anak, dan menyenangkan. Tujuannya selain untuk bermain anak, playground juga sebagai sarana belajar dan stimulasi berbagai aspek perkembangan anak. Melalui playground anak dapat bermain leluasa dan mengembangkan kecerdasannya (Firdaus et al., 2020; Mariyana \& Setiasih, 2018). Desain playground yang baik dapat memfasilitasi pertumbuhan dan perkembangan anak usia dini secara efektif (Diningrat, 2019). 
Adapun bentuk desain playground budaya adalah berisi muatan-muatan budaya yang ada di Indonesia, di antaranya: rumah adat, kesenian, dan alat permainan tradisional. Sebagaimana dijelaskan oleh Fadlillah et al. (2021) bahwa playground budaya merupakan gabungan antara taman bermain dan budaya Indonesia. Desain playground budaya dimaksudkan untuk menumbuhkan cinta tanah air pada anak usia dini. Oleh karena itu, suluruh area bermain sudah dipadukan dengan beberapa kebudayaan Indonesia. Muatan cinta tanah air terdapat pada setiap alat permainan, di mana semuanya sudah dipadukan dengan kebudayaan yang ada di Indonesia, baik untuk alat permainan indoor maupun outdoor.

Dari hasil validasi ahli dan kegiatan FGD disebutkan bahwa dalam playground budaya yang dikembangkan sudah memuat unsur-unsur kebudayaan Indoensia dan sangat bermanfaat sebagai media penanaman cinta tanah air pada anak suia dini. Dalam playground budaya tersebut anak-anak dapat mengetahui berbagai kesenian dan beragam budaya Indonesia lainnya. Sebagaimana dijelaskan oleh Wisnarni (2017) bahwa sikap cinta tanah air salah satunya ialah ditandai dengan menghargai karya seni dan budaya Indonesia. Sejalan dengan itu, rasa cinta tanah air juga ditandai dengan rela berkorban demi kepentingan bangsa dan negara, serta memiliki kecintaan terhadap kebudayaan Indonesia (Kurniawan, 2013). Dengan demikian dapat dipahami bahwa playground budaya ini dapat menjadi sarana bermain dan belajar anak usia dini dalam mengenal kebudayaan Indoensia. Dari kegiatan bermain dan belajar menggunakan playground budaya ini diharapkan mampu menumbuhkan dan menanamkan cinta tanah air sejak usia dini.

\section{SIMPULAN}

Playground budaya adalah zona bermain anak yang dapat diintegrasikan dengan unsur-unsur kebudayaan yang ada di Indonesia. Playground budaya memiliki peran penting dalam menumbuhkan rasa cinta tanah air pada anak usia dini. Desain playground budaya memberikan gambaran bahwa setiap kebudayaan dapat dikenalkan pada anak usia dini dengan cara yang menarik dan menyenangkan. Desain playground budaya ini dapt menjadi langkah awal dalam melakukan inovasi dan kreasi zona bermain anak yang memiliki nilai edukatif bagi perkembangan anak usia dini..

\section{UCAPAN TERIMA KASIH}

Penelitian ini seluruhnya didanai oleh Direktorat Riset dan Pengabdian Masyarakat (DRPM) Kementerian Pendidikan, Kebudayaan, Riset dan Teknologi Republik Indonesia melalui program hibah Penelitian Terapan Unggulan Perguruan Tinggi (PTUPT) dengan nomor kontrak 97/VI.4/PN/2021. Untuk itu, kami ucapkan terimakasih atas kepercayaannya, semoga penelitian ini memberikan manfaat bagi pendidikan anak usia dini di Indonesia. Terimakasih juga disampaikan kepada Universitas Muhammadiyah Ponorogo karena telah memfasilitasi terlaksananya penelitian ini.

\section{DAFTAR PUSTAKA}

Amalia, S., Rofifah, U., \& Zuhri, A. F. (2020). Menampilkan Sikap Cinta Tanah Air Pada Era 4.0. Jurnal Edukatif, 4(01)(1), 68-75.

Atika, N. T., Wakhuyudin, H., \& Fajriyah, K. (2019). Pelaksanaan Penguatan Pendidikan Karakter Membentuk Karakter Cinta Tanah Air. Mimbar Ilmu, 24(1), 105. https://doi.org/10.23887/mi.v24i1.17467

Baskara, M. (2011). Prinsip pengendalian perancangan taman bermain anak di ruang publik. $\begin{array}{llll}\text { Jurnal Lanskap } \quad \text { Indonesia, } & \text { 27-34) }\end{array}$ https://journal.ipb.ac.id/index.php/jli/article/view/5739

Borg, \& G. (2007). An Introduction Education Research (8th ed). Pearson Education, Inc. 
Diningrat, S. W. M. (2019). Design Framework for A School Playground. Jurnal Obsesi : Jurnal Pendidikan Anak Usia Dini, 3(2), 327. https://doi.org/10.31004/obsesi.v3i2.184

Fadlillah, M. (2018). Bermain dan Permainan Anak Usia Dini. Kencana Prenadamedia Group. Fadlillah, M., Rahmawati, I. Y., \& Setyowahyudi, R. (2021). The Concept of a Cultural Playground for Implementing Patriotism in Early Childhood. Advances in Social Science, Education and Humanities Research, 581(Incesh), 233-237.

Fadlillah, M., Rahmawati, I. Y., \& Setyowahyudi, R. (2022). Ragam dan Karakteristik Kebudayaan Indonesia untuk Playground Anak Usia Dini. Unmuh Ponorogo Press.

Firdaus, W., Refianto, R., \& Heru, A. W. (2020). Perancangan playground untuk sarana bermain anak di taman Gasibu. E-Proceeding of Art \& Design, 7(3), 6204-6215. https://openlibrarypublications.telkomuniversity.ac.id/index.php/artdesign/article /view/14234/14017

Little, H., \& Eager, D. (2010). Risk, challenge and safety: Implications for play quality and playground design. European Early Childhood Education Research Journal, 18(4), 497513. https://doi.org/10.1080/1350293X.2010.525949

Luchs, A., \& Fikus, M. (2013). A comparative study of active play on differently designed playgrounds. Journal of Adventure Education and Outdoor Learning, 13(3), 206-222. https:// doi.org/10.1080/14729679.2013.778784

Mariyana, R., \& Setiasih, O. (2018). Pengelolaan Lingkungan Belajar Indoor Outdoor Playground Berbasis Multiple Intelligences Untuk Anak Usia Dini. JPUD - Jurnal Pendidikan Usia Dini, 12(1), 141-152. https:// doi.org/10.21009//JPUD.121.12

Rahayu, R. (2017). Pembelajaran Matematika Realistik Indonesia Berbasis Keunggulan Lokal Untuk Membangun Disposisi Matematis Dan Karakter Cinta Tanah Air. Prosiding Seminar Nasional, 152-163.

Santoso, R. D. (2019). Perancangan Interior Café Playground di Surabaya. 7(2), 211-217.

Stanton-Chapman, T. L., \& Schmidt, E. L. (2019). Building Playgrounds for Children of All Abilities: Legal Requirements and Professional Recommendations. Early Childhood Education Journal, 47(5), 509-517. https:// doi.org/10.1007/s10643-019-00947-3

Sugiyono. (2011). Metode Penelitian Kuantitatif, kualitatif dan R \&amp; D. Bandung: Alfabeta. https:// doi.org/10.1017/CBO9781107415324.004

Wahyuni, F., \& Azizah, S. M. (2020). Bermain dan Belajar pada Anak Usia Dini. Al-Adabiya: Jurnal Kebudayaan Dan Keagamaan, 15(01), 161-179. https:// doi.org/10.37680/adabiya.v15i01.257

Wisnarni. (2017). Menumbuhkembangkan Karakter Cinta Tanah Air Melalui Kegiatan Ekstrakulikuler Berbasis Kebiasaan. Jurnal Tarbawi, 13(119), 51-63. https:// ejournal.iainkerinci.ac.id/index.php/tarbawi/article/view/179

Zaim, F. A., Industri, D. P., Teknik, F., Teknologi, I., Nopember, S., Arief, J., Hakim, R., \& Indonesia, S. (2015). Desain Playground Modular bagi PAUD untuk Lahan Terbatas. $4(2), 12-15$.

Zaini, A. (2019). Bermain sebagai Metode Pembelajaran bagi Anak Usia Dini. ThufuLA: Jurnal Inovasi Pendidikan Guru Raudhatul Athfal, 3(1), 118. https:// doi.org/10.21043/thufula.v3i1.4656 